\title{
Linfogranuloma Venério - Aumento na Incidência Sugere Surto Mundial da Doença
}

\author{
Lymphogranuloma Venereum - Increased Incidence Suggests \\ Diseases World Outbreak
}

\author{
BRUNO DELUCIAHERNANI ${ }^{1}$; SIDNEY ROBERTO NADAL, TSBCP ${ }^{2}$
}

\author{
${ }^{1}$ Acadêmico do $3^{\circ}$ ano da Faculdade de Ciências Médicas da Santa Casa de São Paulo; ${ }^{2}$ Supervisor de Equipe Técnica \\ de Proctologia do Instituto de Infectologia Emílio Ribas. Titular da Sociedade Brasileira de Coloproctologia.
}

HERNANI BL; NADAL SR. Linfogranuloma Venério - Aumento na Incidência Sugere Surto Mundial da Doença. Rev bras Coloproct, 2007;27(2): 224-227.

RESUMO: O Linfogranuloma venéreo (LGV) é uma doença sexualmente transmissível (DST) causada pelos sorotipos L1, L2 ou L3 da bactéria intracelular Chlamydia trachomatis. Possui caráter endêmico em partes da África, Ásia, América do Sul e Caribe, e é rara em países industrializados. No entanto, vários casos foram diagnosticados em homossexuais masculinos, na Holanda, e desde 2004, essa doença vem sendo notificada por outros países da Europa, da América do Norte e Austrália. Esse aumento da incidência tem características de surto, e tem acometido homens brancos com menos de 35 anos que mantém relações sexuais com outros homens e apresentam infecções anorretais com diversos sintomas, que incluem dor retal, tenesmo e constipação. A maior parte dos pacientes (>70\%) também está co-infectada pelo HIV. Depois das primeiras notificações, muitos países passaram a fazer buscas ativas em suas populações. Pela falta de um teste diagnóstico rápido e de uso difundido, os doentes com quadros sugestivos devem receber terapia antimicrobiana durante pelo menos três semanas. Há autores fazendo a mesma recomendação nas retites observadas durante a retoscopia, na presença de mais de 10 leucócitos por campo nas amostras colhidas com swab e nos doentes HIV-positivo. ${ }^{20}$ Acreditamos que o número de casos esteja também aumentando no Brasil e, por desconhecimento sobre a doença, a mesma não venha sendo diagnosticada. Sugerimos que a hipótese diagnóstica de LGV, seja afastada nos doentes que pratiquem sexo anal e apresentem úlceras na região ou quadros de retite.

Descritores: Linfogranuloma venéreo, Chlamydia trachomatis, Proctite, Úlcera anal, Doenças sexualmente transmissíveis.

O Linfogranuloma venéreo (LGV) é uma doença sexualmente transmissível (DST) causada pelos sorotipos L1, L2 ou L3 da bactéria intracelular Chlamydia trachomatis. Possui caráter endêmico em partes da África, Ásia, América do Sul e Caribe, e é rara em países industrializados. ${ }^{1-3}$ No entanto, a partir vários casos diagnosticados em homossexuais masculinos, na Holanda, em 2004, essa doença vem sendo notificada por outros países da Europa, da América do Norte e Austrália. ${ }^{4}$

Após o período de incubação que dura de 3 a 30 dias, na doença primária aparece uma pápula que pode ulcerar no local da inoculação, geralmente no prepúcio ou glande nos homens e na vulva ou parede vaginal nas mulheres. ${ }^{1,5,6}$ Entretanto, essa etapa pode não ocorrer ou passar despercebida. A linfadenopatia inguinal é a manifestação clínica mais comum, surgindo semanas após a lesão primária. Trata-se de gânglios dolorosos e unilaterais que podem formar abscessos e perfurar (bubões). ${ }^{5} \mathrm{~A}$ biópsia dos linfonodos revela área de necrose rodeada por proliferação epitelióide e endotelial. ${ }^{1,6}$ As proctites hemorrágicas ocorrem por inoculação direta, e são mais comuns naqueles que praticam sexo anal. As lesões simulam aquelas das doen-

Trabalho realizado pela Equipe Técnica de Proctologia do Instituto de Infectologia Emílio Ribas e Liga de Coloproctologia da Faculdade de Ciências Médicas da Santa Casa de São Paulo.

$\overline{\text { Recebido em 29/03/2007 }}$

Aceito para publicação em 17/04/2007 
ças inflamatórias dos intestinos. ${ }^{7} \mathrm{O}$ envolvimento anorretal no LGV é raro, ${ }^{1}$ porém os recentes surtos da doença dos países desenvolvidos possuem essa característica.

O LGV pode se tornar crônico quando não tratado, e provocar obstrução linfática por fibrose causando elefantíase genital em ambos os sexos. ${ }^{1,8}$ Além disso, o acometimento retal pode levar a formação de fístulas, abscessos e causar estenose do reto e do canal anal. ${ }^{3}$

O reconhecimento dos casos de LGV é prejudicado, pois a doença não é comum e os profissionais de saúde não estão familiarizados com seus sinais e sintomas. ${ }^{9} \mathrm{O}$ diagnóstico deve ser feito com base nas manifestações clínicas dos doentes, associado à identificação da $C$. trachomatis no local da infecção, por sorologia ou preferencialmente pela reação em cadeia da polimerase (PCR) no material colhido com $s w a b$, que pode detectar o agente e seus sorotipos L1, L2 e L3. ${ }^{10,11}$ Na prática clínica habitual, a detecção pelo DNA não pode ser feita, pois está vinculada somente a grandes centros de pesquisas mundiais. Por isso, o método mais usado, apesar da baixa especificidade, é a sorologia associada ao quadro clínico. ${ }^{3,6}$

O tratamento cura a infecção e previne danos aos tecidos. O antimicrobiano de escolha é a doxiciclina, $100 \mathrm{mg}$, usada por via oral duas vezes ao dia durante três semanas. ${ }^{11}$ A azitromicina $1 \mathrm{~g}$, dose única, uma vez por semana, durante três semanas, mostrou sucesso, segundo alguns autores, ${ }^{10}$ embora, não haja estudos bem controlados confirmando sua eficácia em doentes soropositivos para o vírus da imunodeficiência humana (HIV). ${ }^{12}$ A eritromicina oral de $500 \mathrm{mg}$, tomadas quatro vezes ao dia, durante três semanas, é um tratamento alternativo, ${ }^{11}$ melhor indicado para gestantes. ${ }^{5}$ Os pacientes serão acompanhados até que os sinais e sintomas desapareçam. Os gânglios inflamados devem ser drenados ou aspirados através da pele íntegra, para evitar a ocorrência de fístulas e ulcerações. ${ }^{5}$

Tão importante quanto a cura é a pesquisa da infecção nos parceiros sexuais dos últimos 30 dias antes do aparecimento dos primeiros sintomas. Essas pessoas devem ser examinadas e testadas para infecção pela Chlamydia, além de receber medicação em caráter profilático. ${ }^{5,11} \mathrm{O}$ aumento do número de casos na Europa, na Austrália e na América do Norte, tem características de surto. ${ }^{11} \mathrm{O}$ LGV tem acometido homens brancos com menos de 35 anos, que mantém relações sexuais com outros homens ${ }^{4}$ e apresentam infecções anorretais com diversos sintomas, que incluem dor retal, tenesmo e constipação. ${ }^{9}$ A maior parte dos pacientes $(>70 \%)$ também está co-infectada pelo HIV. ${ }^{3,4,11}$

Até dezembro de 2005, 179 casos foram confirmados na Holanda, ${ }^{4}$ sendo que os primeiros 13 doentes foram diagnosticados entre abril e novembro de 2003 em Rotterdam. A maioria dos doentes era HIVpositivo e relatava intercursos anais com diferentes parceiros no último ano. Somente um deles apresentou a úlcera e a linfadenopatia clássicas da LGV. Os demais relataram sintomas gastrointestinais tais como proctite hemorrágica e constipação. Dois casos foram identificados em janeiro de 2004, na Bélgica, ambos ligados ao surto holandês. Subseqüentemente, durante a rotina no centro de controle de DST, mais nove outros foram detectados e com as mesmas características clínicas dos pacientes holandeses. ${ }^{13}$

Por sua raridade, o LGV não vinha sendo pesquisado como diagnóstico diferencial das retites hemorrágicas. ${ }^{14}$ Depois das primeiras notificações dos surtos de LGV, muitos países passaram a fazer buscas em suas populações. Na França, 244 doentes com acometimento retal foram identificados até dezembro de $2005 .{ }^{4} \mathrm{Na}$ Alemanha, 61 outros, até novembro de $2005 .{ }^{4}$ Em outubro de 2004, no Reino Unido iniciou-se campanha para diagnóstico da doença, utilizando questionários e testes de genótipo dos sorotipos L1, L2 e L3. Até fevereiro de 2006, confirmaram 327 casos, principalmente nas redondezas de Londres e Brighton. Desses, $96 \%$ apresentavam proctite associada a diversos sintomas locais e sistêmicos, $76 \%$ eram co-infectados pelo HIV, $19 \%$ com Hepatite C e $39 \%$ apresentavam outras DST. ${ }^{15} \mathrm{O}$ LGV também vem sendo mais diagnosticado na América do Norte ${ }^{16}$ e na Austrália, ${ }^{17}$ sugerindo haver um surto com disseminação global, propiciado pela facilidade atual de locomoção, inclusive intercontinental. ${ }^{18}$

O LGV não é doença de notificação compulsória na maioria dos países, dificultando as ações de saúde pública. ${ }^{4}$ Com os diversos dados atuais mostrando surtos em países desenvolvidos, as autoridades de saúde devem estar atentas para a ocorrência de novos casos doença e rastreamento dos parceiros sexuais. ${ }^{19}$ Pela falta de um teste diagnóstico rápido e de uso difundido, os doentes com quadros sugestivos de LGV devem receber terapia antimicrobiana durante pelo menos três semanas. ${ }^{12}$ Há autores fazendo a mesma recomendação nas retites detectadas durante a 
retoscopia, na presença de mais de 10 leucócitos por campo nas amostras colhidas com swab, e nos doentes HIV-positivo. ${ }^{20}$ Acreditamos que o número de casos esteja também aumentando no Brasil e, por desco- nhecimento, a doença não venha sendo diagnosticada. Sugerimos que a hipótese diagnóstica de LGV seja afastada nos doentes que pratiquem sexo anal e apresentem retite ou úlceras na região.

ABSTRACT: Lymphogranuloma venereum (LGV) is a sexually transmitted disease (STD) caused by L1, L2 L3 sorovars of the intracellular bacteria Chlamydia trachomatis. It has endemic features in parts of Africa, Asia, South America and Caribbean, and is rare in developed countries. Meanwhile, many cases were diagnosed, mainly in men who have sex with men (MSM), in the Netherlands, and since 2004, this disease has been notified by other European countries, North America and Australia. This increased incidence seems like an outbreak and common features in these reports were: MSM, Caucasian race / ethnicity, mean age above 35 years, predominantly (>70\%) co-infected with HIV. Complaints included anorectal pain, tenesmus and constipation. After these reports, many countries started doing active research in their people. The lack of a specific diagnostic test has complicated LGV case ascertainment. In the absence of laboratory confirmation of $L$ serovars, patients with symptoms suggestive of LGV should be presumptively treated with antibacterial therapy for 3 weeks. If routine LGV serovar typing is unavailable, most authors proposed administration of syndromic LGV treatment for MSM with anorectal chlamydia and either proctitis detected by proctoscopic examination, more than 10 white blood cells/high-power field detected on an anorectal smear specimen, or HIV seropositivity. We believed the incidence of LGV is also increasing in Brazil, and new cases are not being diagnosed because the ignorance about this world outbreak. We suggest that anal ulcer or proctitis in anal sex practitioners must have a high suspicious of LGV infection.

Key words: Lymphogranuloma venereum, Chlamydia trachomatis, Proctitis, Anal, ulcer, Sexually transmitted diseases.

\section{REFERÊNCIAS}

1. Mabey D, Peeling RW. Lymphogranuloma venereum. Sex Transm Infect 2002;78:90-92.

2. Simms I, Ward H, Martin I, Alexander S, Ison C. Lymphogranuloma venereum in Australia. Sex Health 2006;3:131-3.

3. Collins L, White JA, Bradbeer C. Lymphogranuloma venereum. BMJ 2006;332:66.

4. Van de Laar M. The emergence of LGV in Western Europe: what do we know, what can we do? Euro Surveill 2006;11:146-8.

5. Centers for Disease Control and Prevention, Workowski KA, Berman SM. Sexually transmitted diseases treatment guidelines, 2006. MMWR Recomm Rep. 2006;55:1-94.

6. Vall-Mayans M, Noguer I. Brotes de linfogranuloma venéreo entre hombres homosexuales em Europa, 2003-2004. Enferm Infecc Microbiol Clin 2006;24:137-138.

7. Ahdoot A, Kotler DP, Suh JS, Kutler C, Flamholz R. Lymphogranuloma venereum in human immunodeficiency virus-infected individuals in New York City. J Clin Gastroenterol. 2006;40:385-90.

8. Gupta S, Ajith C, Kanwar AJ, Sehgal VN, Kumar B, Mete U. Genital elephantiasis and sexually transmitted infections revisited. Int J STD AIDS. 2006;17:157-65.

9. Van de Laar M, Fenton K, Ison C, European Surveillance of Sexually Transmitted Infections (ESSTI). Update on the European lymphogranuloma venereum epidemic among men who have sex with men. Euro Surveill 2005;10:E050602.1.
10. Nieuwenhuis RF, Ossewaarde JM, Gotz HM, Dees J, Thio $\mathrm{HB}$, Thomeer MG, et al. Resurgence of lymphogranuloma venereum in Western Europe: an outbreak of Chlamydia trachomatis serovar 12 proctitis in The Netherlands among men who have sex with men. Clin Infect Dis. 20041;39:996-1003.

11. Centers for Disease Control and Prevention (CDC) Lymphogranuloma venereum among men who have sex with men-Netherlands, 2003-2004. MMWR Morb Mortal Wkly Rep. 2004;53:985-8.

12. McLean CA, Stoner BP, Workowski KA. Treatment of lymphogranuloma venereum. Clin Infect Dis. 2007;44:S14752.

13. Vandenbruaene M, Ostyn B, Crucitti T, De Schrijver K, Sasse A, Sergeant M, et al. Lymphogranuloma venereum outbreak in men who have sex with men (MSM) in Belgium, January 2004 to July 2005. Euro Surveill 2005;10:E050929.3.

14. Pathela P, Blank S, Schillinger JA. Lymphogranuloma venereum: old pathogen, new story. Curr Infect Dis Rep. 2007;9:143-50.

15. Ward H, Martin I, Macdonald N, Alexander S, Simms I, Fenton $\mathrm{K}$ et al. Lymphogranuloma venereum in the United Kingdom. Clin Infect Dis 2007;44:26-32.

16. Tinmouth J, Rachlis A, Wesson T, Hsieh E. Lymphogranuloma venereum in North America: case reports and an update for gastroenterologists. Clin Gastroenterol Hepatol 2006; 4:469-73.

17. Morton AN, Fairley CK, Zaia AM, Chen MY. Anorectal lymphogranuloma venereum in a Melbourne man. Sex Health 2006;3:189-90. 
18. Nadal SR, Manzione CR. Identificação dos grupos de risco para as doenças sexualmente transmitidas. Rev Bras Coloproct 2003;23:128-129.

19. Richardson D, Goldmeier D. Lymphogranuloma venereum: an emerging cause of proctitis in men who have sex with men. Int J STD AIDS. 2007;18:11-4.

20. Van der Bij AK, Spaargaren J, Morre SA, Fennema HS, Mindel A, Coutinho RA, et al. Diagnostic and clinical implications of anorectal lymphogranuloma venereum in men who have sex with men: a retrospective case-control study. Clin Infect Dis. 2006;42:186-94.
Endereço para correspondência: SIDNEY ROBERTO NADAL

Rua Dr. Virgilio de Carvalho Pinto, 381 / Apto. 23

São Paulo (SP) - Brasil

CEP 05415-030

Tel./Fax (+55 11) 3337-4282

E-mail:srnadal@terra.com.br 